\title{
Mangotoxin production of Pseudomonas syringae pv. syringae is regulated by MgoA
}

\author{
Víctor J Carrión 1,3,4, Menno van der Voort ${ }^{3}$, Eva Arrebola2 , José A Gutiérrez-Barranquero ${ }^{1,5}$, Antonio de Vicente
} Jos M Raaijmakers ${ }^{3,4}$ and Francisco M Cazorla ${ }^{1 *}$

\begin{abstract}
Background: The antimetabolite mangotoxin is a key factor in virulence of Pseudomonas syringae pv. syringae strains which cause apical necrosis of mango trees. Previous studies showed that mangotoxin biosynthesis is governed by the mbo operon. Random mutagenesis led to the identification of two other gene clusters that affect mangotoxin biosynthesis. These are the gacS/gacA genes and mgo operon which harbors the four genes mgoBCAD.

Results: The current study shows that disruption of the nonribosomal peptide synthetase (NRPS) gene mgoA resulted in loss of mangotoxin production and reduced virulence on tomato leaves. Transcriptional analyses by qPCR and promoter reporter fusions revealed that mbo expression is regulated by both gacS/gacA and mgo genes. Also, expression of the mgo operon was shown to be regulated by gacS/gacA. Heterologous expression under the native promoter of the mbo operon resulted in mangotoxin production in non-producing $P$. syringae strains, but not in other Pseudomonas species. Also introduction of the mbo and mgo operons in nonproducing $P$. protegens Pf-5 did not confer mangotoxin production but did enhance transcription of the mbo promoter.
\end{abstract}

Conclusions: From the data obtained in this study, we conclude that both $m b o$ and $m g o$ operons are under the control of the gacS/gacA two-component system and that the MgoA product acts as a positive regulator of mangotoxin biosynthesis.

Keywords: Antimetabolite toxin, mgo operon, GacS/GacA, Plant-microbe interaction

\section{Background}

Pseudomonas syringae is one of the most ubiquitous plant pathogens, causing various economically important diseases [1]. The present study focuses on $P$. syringae pv. syringae UMAF0158 (CECT 7752) which causes apical necrosis of mango $[2,3]$. The antimetabolite mangotoxin is a key virulence factor of strain UMAF0158 $[4,5]$. This toxin is produced in the early exponential growth phase and inhibits ornithine $N$-acetyl transferase, a key enzyme belonging to the ornithine/arginine biosynthetic pathway [2].

Random mini-Tn 5 mutagenesis followed by cloning, sequencing and heterologous expression recently led to the identification of the gene cluster that governs mangotoxin biosynthesis [6]. The mbo operon (mangotoxin biosynthetic

\footnotetext{
* Correspondence: cazorla@uma.es

1 Departamento de Microbiología, Facultad de Ciencias, Instituto de Hortofruticultura Subtropical y Mediterránea "La Mayora"-Universidad de Málaga-Consejo Superior de Investigaciones Científicas (IHSM-UMA-CSIC), Universidad de Málaga, Campus de Teatinos, 29071 Málaga, Spain Full list of author information is available at the end of the article
}

operon) is composed of six genes, $m b o A B C D E F$. Disruption of each of these genes resulted in mangotoxin deficient mutants and constitutive expression of the $m b o$ operon in non-mangotoxin producing $P$. syringae strains conferred mangotoxin production [6]. Screening of the random mutant library also led to the identification of several other genes that may be involved in the regulation of mangotoxin biosynthesis [4]. These included the gacS/gacA genes and the so-called mangotoxin generating operon $m g o[6,7]$.

The GacS/GacA two-component regulatory system is highly conserved in Gram-negative bacteria and is involved in a variety of functions, including pathogenicity [8], quorum sensing $[9,10]$, secondary metabolite production [11-14] and biofilm formation [15-17]. In Pseudomonas syringae, the GacS/GacA two-component system regulates the production of the phytotoxins syringomycin and syringopeptin [18-20], tabtoxin [21,22] and phaseolotoxin [23]. In $P$. syringae pv. tomato DC3000, GacS/GacA regulate the $h r p R$, $h r p S$, and $h r p L$ genes, which are required for the activation of the Hrp 
type III secretion and effector genes [24,25]. However, in P. syringae pv. syringae B728a, GacA appears not to be required for hrp gene expression [25].

The $m g o$ operon is composed of four genes, $m g o B C A D$ $[4,7]$. Mutants in each gene belonging to the $m g o$ operon showed an alteration ( $m g o B$ mutant) or lack of mangotoxin production ( $m g o C$, $m g o A$ and $m g o D$ mutants). These genes encode for different hypothetical proteins with predicted domains for a haem oxygenase (MgoB), a $p$-aminobenzoate $\mathrm{N}$-oxygenase (MgoC), a nonribosomal peptide synthetase (MgoA), and a polyketide cyclase/ dehydrase or lipid transporter (MgoD) [4,7]. The predicted amino acid sequence of MgoA suggests only one amino acid activation module and 14 conserved domains, including aminoacyl adenylation, condensation, thiolation, and additional reduction domains [4]. Genes homologous to the mgo operon have been found in the genomes of most Pseudomonas spp., with the exception of $P$. protegens Pf-5 and CHAO [26,27]. Recent studies on the $p v f$ gene cluster in P. entomophila, a homologue of the mgo operon, suggested that it affects virulence [28]. Almost all the fluorescent Pseudomonas spp. lack the $m b o$ operon $[29,30]$, but the $m g o$ operon is conserved in all of them (except $P$. protegens $\mathrm{Pf}-5$ ) [4,7,26-28]. To date, however, the functions of mgo operon are yet unknown.

The overall objective of this study was to get insight into the role of the mgo operon in regulation of mangotoxin production in P. syringae pv. syringae UMAF0158 and unravel the interplay between $m g o, m b o$ and the gacS/gacA two-component regulatory system.

\section{Methods}

\section{Bacterial strains and culture conditions}

The wild type strain $P$. syringae pv. syringae UMAF0158 (CECT 7752) and the collection of selected derivative mutants used in this study (Table 1) were grown on Pseudomonas agar F (Difco) plates, in liquid King's medium B (KMB) [31] or in Pseudomonas minimal medium (PMS) [32] at $28^{\circ} \mathrm{C}$. Escherichia coli strain DH5 $\alpha$ was used as a host for plasmid complementation experiments. It was routinely grown on Luria-Bertani (LB) plates or in LB broth at $37^{\circ} \mathrm{C}$. Antibiotics for selection of $P$. syringae pv. syringae UMAF0158 and E. coli derivatives were ampicillin $\left(100 \mathrm{mg} \mathrm{L}^{-1}\right)$, kanamycin $\left(50 \mathrm{mg} \mathrm{L}^{-1}\right)$, gentamycin $\left(30 \mathrm{mg} \mathrm{L}^{-1}\right)$ or tetracycline $\left(25 \mathrm{mg} \mathrm{L}^{-1}\right)$.

\section{Mangotoxin production assay}

Antimetabolite toxin production was assayed by the indicator technique previously described [32]. Briefly, a double layer of the indicator microorganism E. coli CECT 831 was prepared; after solidification, the $P$. syringae pv. syringae strains to be tested were stab-inoculated. The plates were initially incubated at $22^{\circ} \mathrm{C}$ for $24 \mathrm{~h}$, and then at $37^{\circ} \mathrm{C}$ for an additional $24 \mathrm{~h} \mathrm{[2]}$. To evaluate mangotoxin activity, the same plate bioassay was carried out with the addition of $100 \mu \mathrm{l}$ of a $6 \mathrm{mM}$ solution of $N$-acetyl-ornithine or L-ornithine to the double layer of E. coli [2]. To determine growth characteristics of representative strains, the wild type mangotoxin-producing $P$. syringae $\mathrm{pv}$. syringae UMAF0158 and derivatives mutants in $m b o A, m g o A$ and gacA genes were used to obtain initial cultures in $10 \mathrm{ml}$ of LB broth. The bacterial strains were grown during $24 \mathrm{~h}$ at $28^{\circ} \mathrm{C}$ to prepare an optimal bacterial inoculum with an optical density of 0.8 at $600 \mathrm{~nm}$ (approximately $10^{9} \mathrm{cfu} \mathrm{m}^{-1}$ ). One $\mathrm{ml}$ from these bacterial inocula was used to inoculate $100 \mathrm{ml}$ of PMS broth. The cultures were incubated at $22^{\circ} \mathrm{C}$ under orbital shaking at $150 \mathrm{rpm}$ until the stationary phase. Samples were collected every 6 or $12 \mathrm{~h}$ to monitor the bacterial growth. Bacterial cfu per sample were determined by 10-fold serial dilutions on KMB plates. At the same time, the mangotoxin production assessment was performed by a cell-free filtrate dilution sequence at $50 \%$. The mangotoxin production is measured using arbitrary units, which can be defined as the relative toxic volume of cell free filtrates of liquid cultures, which produces an inhibition halo of $18 \mathrm{~mm}$ in diameter under standard assay conditions [2]. The methodology presented a detection threshold of 0.5 toxic units, due to the diameter of the wells where the cell-free filtrate were deposited $(9 \mathrm{~mm})$.

\section{Complementation experiments}

DNA fragments of approximately $7 \mathrm{~kb}$ containing the $m g o$ and $m b o$ operons, including the promoter and terminator regions, were obtained by PCR using specific primers (Additional file 1: Table S1) and high fidelity polymerase (Phusion DNA polymerase, Finnzymes). The PCR amplification products were cloned in pGEM-T Easy (Promega), and the plasmids obtained were digested with $\mathrm{XbaI}$ for the mgo operon and with EcoRI and PstI for the mbo operon. After the digestion, both operons fragment were obtained from gel with the NucleoSpin kit (GE Healthcare) and cloned into the correspondent shuttle vectors, pBBR1MCS5 [36] for the mgo operon and pMP220 [37] for the $m b o$ operon, which were digested, dephosphorylated (shrimp alkaline phosphatase; Promega), and purified with the NucleoSpin kit according to the manufacturer's instructions. E. coli DH5 $\alpha$ was transformed with the plasmids obtained, by heat shock transformation [38], and transformed colonies were selected on LB agar plates supplemented with gentamicin $\left(30 \mathrm{mg} \mathrm{L}^{-1}\right)$ in the case of pBBR1MCS-5 and tetracycline $\left(25 \mathrm{mg} \mathrm{L}^{-1}\right)$ for pMP220. Plasmids with the $m g o$ and $m b o$ operon cloned were obtained (Table 1). Correct integration and orientation of the fragments was verified by PCR and restriction analysis of isolated plasmids (data not shown). The pLac-mgoBCAD construct was subsequently electroporated into the $m b o A, m g o A$ and gacA 
Table 1 Bacterial strains and plasmids used in this study

\begin{tabular}{|c|c|c|}
\hline $\begin{array}{l}\text { Strain or } \\
\text { plasmid }\end{array}$ & Relevant characteristics & $\begin{array}{l}\text { Reference/ } \\
\text { source }\end{array}$ \\
\hline \multicolumn{3}{|l|}{ Strains } \\
\hline \multicolumn{3}{|l|}{ E. coli } \\
\hline $\mathrm{DH} 5 \mathrm{a}$ & E. coli [F' Ф80lacZ M15 $\triangle($ lacZYA-argF)U169 deoR recA endA1 hsdR17 (rK-mK+)phoA supE44 lambda- thi-1] & [33] \\
\hline CECT831 & Indicator strain for mangotoxin production & $\mathrm{CECT}^{\mathrm{a}}$ \\
\hline \multicolumn{3}{|c|}{ P. syringae pv. syringae } \\
\hline B728a & Complete genome, non-mangotoxin producer & [34] \\
\hline UMAF0158 & Wild type, isolated from mango, mangotoxin producer, $\mathrm{Nf}^{\mathrm{r}}$ & [2] \\
\hline$m b o A^{-}$ & Derivative mutant of UMAF0158 by insertion in $m b \circ A, \mathrm{Km}^{r}, \mathrm{Nf}^{r}$ (named $\mathrm{mboA}^{-}$) & [6] \\
\hline$\triangle m g \circ A$ & Derivative mutant of UMAF0158 by deletion of $m g \circ A, \mathrm{Nf}^{r}$ (named $\Delta \mathrm{mgoA}$ ) & [7] \\
\hline $2 \beta B 7$ & miniTn5 mutant of UMAF0158 in gacA defective in mangotoxin, $\mathrm{Km}^{r}, \mathrm{Nf}^{\mathrm{r}}$ (named gacA) & [4] \\
\hline $3 a E 10$ & miniTn5 mutant of UMAF0158 in gacS defective in mangotoxin, $\mathrm{Km}^{\mathrm{r}}$, Nf'(named gacS') & [2] \\
\hline $3 \gamma \mathrm{H} 1$ & miniTn5 mutant of UMAF0158, defective in mangotoxin production, $\mathrm{Km}^{\mathrm{r}}$, Nf $\mathrm{f}^{\mathrm{r}}$ & [2] \\
\hline $4 \beta A 2$ & miniTn5 mutant of UMAF0158, defective in mangotoxin production, $\mathrm{Km}^{r}, \mathrm{Nf}^{r}$ & [2] \\
\hline $5 \mathrm{aC5}$ & miniTn5 mutant of UMAF0158, defective in mangotoxin production, $\mathrm{Km}^{r}, \mathrm{Nf}^{r}$ & [2] \\
\hline $6 \gamma F 6$ & miniTn5 mutant of UMAF0158, defective in mangotoxin production, $\mathrm{Km}^{r}$, Nf ${ }^{r}$ & [2] \\
\hline $\begin{array}{l}\text { P. protegens } \\
\text { Pf-5 }\end{array}$ & Non mangotoxin producer, mbo and mgo operon absent & {$[35]$} \\
\hline \multicolumn{3}{|l|}{ Plasmids } \\
\hline pBBR1MCS-5 & $4.7 \mathrm{~kb}$ broad-host-range cloning vector, $\mathrm{Gm}^{\mathrm{r}}$ & [36] \\
\hline pGEM-T & $3.0 \mathrm{~kb}$ cloning vector, $\mathrm{Ap}^{\mathrm{r}}$ & Invitrogen \\
\hline pGEM-TBCAD & mgoBCAD cloned in pGEM-T, Ap ${ }^{r}$ & This study \\
\hline $\begin{array}{l}\text { pLac- } \\
\text { mgoBCAD }\end{array}$ & $\begin{array}{l}\text { mgoBCAD cloned in pBBR1MCS-5 downstream the lacZ promoter in the vector, mgo operon expression under its own } \\
\text { and } P_{L A C} \text { promoter, Gm }{ }^{r}\end{array}$ & This study \\
\hline $\begin{array}{l}\text { pLac- } \\
\text { mboABCDEF }\end{array}$ & $\begin{array}{l}\text { mboABCDEF cloned in pBBR1MCS-5 downstream the lacZ promoter in the vector, mbo operon expression under its own } \\
\text { and } P_{L A C} \text { promoter, } \mathrm{Gm}^{r}\end{array}$ & {$[6]$} \\
\hline $\begin{array}{l}\text { pLac- } \\
\text { mboFEDCBA }\end{array}$ & $\begin{array}{l}\text { mboABCDEF cloned in pBBR1MCS-5 in the opposite direction than the lacZ promoter in the vector, mbo operon expres- } \\
\text { sion under its own promoter, Gm }\end{array}$ & [6] \\
\hline pMP220 & Promoter-probe vector containing a promoterless LacZ gene, Tet ${ }^{r}$ & [37] \\
\hline $\begin{array}{l}\text { PMP- } \\
\text { mbOABCDEF }\end{array}$ & $\begin{array}{l}\text { mboABCDEF cloned in promoter-probe vector containing a promoterless LacZ gene, mbo operon expression under its } \\
\text { own promoter, Tet }{ }^{r}\end{array}$ & This study \\
\hline pMP:::P $P_{\text {mbol }}$ & pMP220 vector containing the mbo operon promoter, Tet $^{r}$ & {$[6]$} \\
\hline
\end{tabular}

${ }^{a}$ CECT: Spanish Type Culture Collection, Spain.

mutants, and the wild-type strains $P$. syringae pv. syringae UMAF0158 and $P$. protegens Pf-5. The pMP-mboABCDEF construct was transformed in $P$. protegens Pf- 5 which previously contain the pLac-mgoBCAD, therefore this bacteria finally harbored both operons, the $m g o$ and $m b o$ operon. Transformed cells were selected on KMB agar supplemented with correspondent antibiotics. The presence of the different plasmids was confirmed by PCR analysis with specific primers for pBBR1MCS-5 and pMP220 and plasmid profiling.

\section{Virulence evaluation}

The virulence of different mangotoxin producing or non-producing $P$. syringae pv. syringae strains were analyzed in detached tomato leaflets (Solanum lycopersicum
Mill.) cv. Hellfrucht Frühstamm maintained in vitro using Murashige and Skoog medium (MS, SigmaAldrich) $[4,5]$. Bacterial suspensions from exponentially growing cultures were adjusted to $10^{8} \mathrm{cfu} \mathrm{ml}^{-1}$. The leaflets were inoculated by placing six $10 \mu \mathrm{l}$ drops of the bacterial suspension on six different points on the same leaflet. Inoculations were then carried out by piercing through the droplets with a sterile entomological pin. The leaflets were maintained in MS media at $22^{\circ} \mathrm{C}$ and a 16:8-h light: dark photoperiod. Six tomato leaflets were used to evaluate each strain. Detached leaflets only inoculated with sterile distilled water were included in all experiments as a control. These experiments were repeated three times. The development of necrotic symptoms at the inoculation points $(\mathrm{n}=108)$ was 
determined after 10-day. The severity symptoms were evaluated by the analysis of the total necrotic area per leaflet induced by the inoculated strains after 10 days of incubation. For severity measurement, the necrotic areas of the inoculation points were digitally analyzed on the six leaflets, using the computer image software VISILOG 5.0 (Noesis Vision Inc.). At the same time, two inoculated leaflets were used to estimate the daily development of the total bacterial population. For that purpose, whole tomato leaflets were homogenized in sterile water and bacterial counts were determined plating by 10 -fold serial dilutions on KMB plates. Bacterial growth inside the plant tissue was recorded after $\mathrm{H}_{2} \mathrm{O}_{2}$ leaf surface disinfection. Colony counts growth based on the typical morphology of $P$. syringae pv. syringae UMAF0158 were recorded after incubation at $28^{\circ} \mathrm{C}$ for $48 \mathrm{~h}$.

\section{Transcriptional analysis}

From PMS cultures described above, cells from $2 \mathrm{ml}$ cultures were collected and spun down at 12,000 rpm (1 min) from the wild type strain and the derivative mutants in gacA and $m g o A$. The cells were frozen in liquid $\mathrm{N}_{2}$ and stored at $-80^{\circ} \mathrm{C}$. For the RNA isolations and cDNA synthesis, three biological replicates were used for each time point. For the transcriptional analyses, RNA was isolated from the frozen bacterial cells with Trizol reagent (Invitrogen), followed by DNase I (GE Healthcare) treatment. One $\mu \mathrm{g}$ of RNA was used for cDNA synthesis with Superscript III (Invitrogen) according to the manufacturer's protocol. For the real-time quantitative PCR (Q-PCR), conducted with the 7300SDS system from Applied Biosystems, the SYBR Green Core kit (Eurogentec) with a final concentration of $3.5 \mathrm{mM} \mathrm{MgCl} 2$ was used according to the manufacturer's protocol. The concentration of the primers was optimized ( $400 \mathrm{nM}$ final concentration for all of them), and a dissociation curve was performed to check the specificity of the primers. The primers used for the Q-PCR are listed in Additional file 1: Table S1. To correct for small differences in template concentration, $r p o D$ was used as the reference housekeeping gene. The cycle in which the SYBR green fluorescence crossed a manually set cycle threshold $\left(C_{T}\right)$ was used to determine transcript levels. For each gene, the threshold was fixed based on the exponential segment of the PCR curve. The $C_{T}$ value of $m b o A$ was corrected for the housekeeping gene rpoD as follows: $\Delta C_{T}=C_{T}(\mathrm{mboA})-C_{T}$ (rpoD); the same formula was used for the other genes studied. The relative quantification (RQ) values were calculated by the following formula: $R Q=$ $2^{-[\Delta C T \text { (mutant) }-\Delta C T \text { (wild type) }]}[39,40]$. Q-PCR analysis was performed in duplicate (technical replicates) on three independent RNA isolations (biological replicates).

\section{$\beta$-galactosidase assays}

To study the mbo operon expression in different genetic backgrounds, the mbo operon promoter $\left(\mathrm{P}_{m b o I}\right)$ cloned into pMP220 [19] as previously described [6] was used. The derivative mutants in $m g o A$, gacA and gacS genes were transformed with plasmid $\mathrm{pMP}:: \mathrm{P}_{m b o I}$ which contains the $\mathrm{P}_{m b o l}$. The plasmid pLac-mgoBCAD (harboring the mgo operon) was also used to complement the $m g o A$, gacA and gacS mutants and finally the $\beta$ galactosidase activity of $\mathrm{P}_{m b o I}$ was measured. In order to evaluate the effect of the $m g o$ operon on the activity of $\mathrm{P}_{\text {mbor }}$, P. protegens $\mathrm{Pf}-5$ was used due to the absence of the two operons in its genome. First, $P$. protegens Pf-5 was transformed with the pMP:: $\mathrm{P}_{m b o I}$ and the promoter activity was measured, and secondly to measure the effect on the mbo operon transcription, this strain containing the plasmid $\mathrm{pMP}:: \mathrm{P}_{m b o I}$, was also transformed with the plasmid pLac-mgoBCAD ( $m g o$ operon under pLac regulation). As a negative control the $\beta$ galactosidase activity was measured for the wild type strain $P$. syringae pv. syringae UMAF0158 and each strain used in this assay, transformed with empty vector pMP220. $\beta$-galactosidase activities were quantified by the Miller method [41]. Briefly, an overnight culture obtained as previously described in growth curve and toxins assay section were prepared. The samples were collected at $18 \mathrm{~h}$, and the cells were harvested and suspended in assay buffer to eliminate any error in the detection of $\beta$-galactosidase activity due to the effects of different carbon sources present in the growth medium. The results presented are from three separate experiments, each conducted in triplicate.

\section{Phylogeny of the mgoA gene}

In order to identify the presence of the $m g o A$ gene in the different genomes of Pseudomonas strains, the $m g o A$ gene from $P$. syringae pv. syringae UMAF0158 was used in BLASTP [42] comparisons with whole genome sequences of Pseudomonas spp. available in the databases. Once the amino acid sequences of all the orthologous $m g o A$ genes were obtained, the putative adenylation domains were identified using the PKS/NRPS Analysis Web-site (http://nrps. igs.umaryland.edu/nrps) [43]. Other adenylation domains of which the activated amino acid is already known were obtained from the database and from De Bruijn met al. [44]. Two phylogenetic analyses were done, the first was using the adenylation domain of all the NRPSs (328 residues) and the second was using the almost entire sequence of MgoA (1015 residues). Amino acid sequences were aligned with Muscle (MEGA5 software) and determination of the optimal amino acid substitution model and phylogenetic tree construction were done using MEGA5 software [45]. Neighbor-joining, maximum parsimony and maximum-likelihood phylogenetic trees of the individual 
gene sequences were generated in MEGA5 by using the optimal model parameters and the option of complete deletion to eliminate positions containing gaps. Confidence levels for the branching points were determined using 1,000 bootstrap replicates.

\section{Bioinformatics and statistical analysis}

Searches for sequence similarity in the NCBI databases were carried out using BLAST algorithms [42]. Genome and nucleotide sequences were visualized and manipulated using the Artemis genome browser [46] and compared using ACT [47] in combination with WebACT [48]. The statistical analysis of incidence was performed by SAS9.2 software (SAS Institute Inc.) by Enterprise Guide 4.2 using generalized linear model analysis. The $\beta$-galactosidase and the necrotic area data were statistically analyzed using an analysis of variance, followed by Fisher's least significant difference test $(\mathrm{p}=0.05)$, and for $\beta$-galactosidase activity on $P$. protegens Pf5, a Student's $t$-test was carried out $(\mathrm{p}=0.05)$, using the IBM.SSPS 19 software (IBM ${ }^{\bullet}$ Company).

\section{Results}

Involvement of mbo genes in mangotoxin production and virulence in $P$. syringae pv. syringae UMAF0158

Six mangotoxin deficient mutants of $P$. syringae pv. syringae UMAF0158, were previously obtained and characterized for mangotoxin production (Table 1 and Figure 1). Mangotoxin characterization showed that although these mutants did not show mangotoxin production, a slight production of a yet unknown antimicrobial compound was observed for mutants $4 \beta A 2(m b o B)$ and $5 \alpha C 5(m b o D)$ (Figure 1). For two mutants $(3 \gamma \mathrm{H} 1$ and $6 \gamma \mathrm{F} 6)$, the Tn5 insertion was located in $m g o C$ and $m g o A$ respectively. Two other non-mangotoxin producing mutants were disrupted in the genes encoding the GacS/GacA two-component regulatory system ( $3 \alpha \mathrm{E} 10$ and $2 \beta \mathrm{B} 7$ respectively). Growth of the $m g o A$ mutant was shown to be similar to that of the

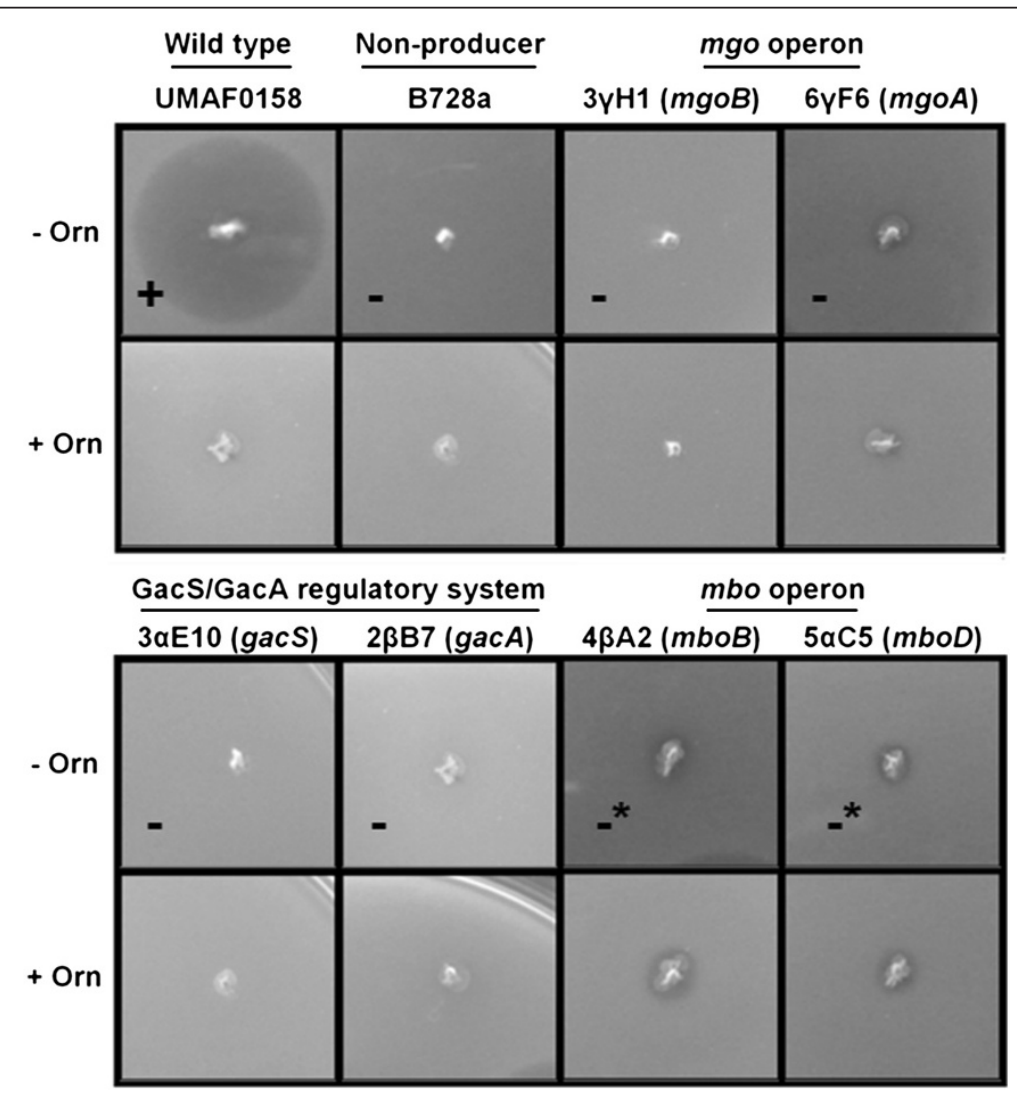

Figure 1 Mangotoxin production by random miniTn 5 insertional mutants. Three pairs of mutants in different genes of the mbo and mgo operon, and in the gacS/gacA two-component regulatory system, obtained in previous works and tested for mangotoxin production. The corresponding disrupted gene is detailed in brackets. The P. syringae pv. syringae strains UMAF0158 (mangoxin-producing wilt-type strain) and B728a (nonproducing) were used as references. Mangotoxin production was evaluated using PMS minimal medium supplemented or not with ornithine. The results are indicated as follows: - absence of inhibition halo, + presence of inhibition halo, -* slight toxicity which was not reverted by addition of ornithine. Toxic activity reverted in presence of ornithine denotes the production of mangotoxin. 


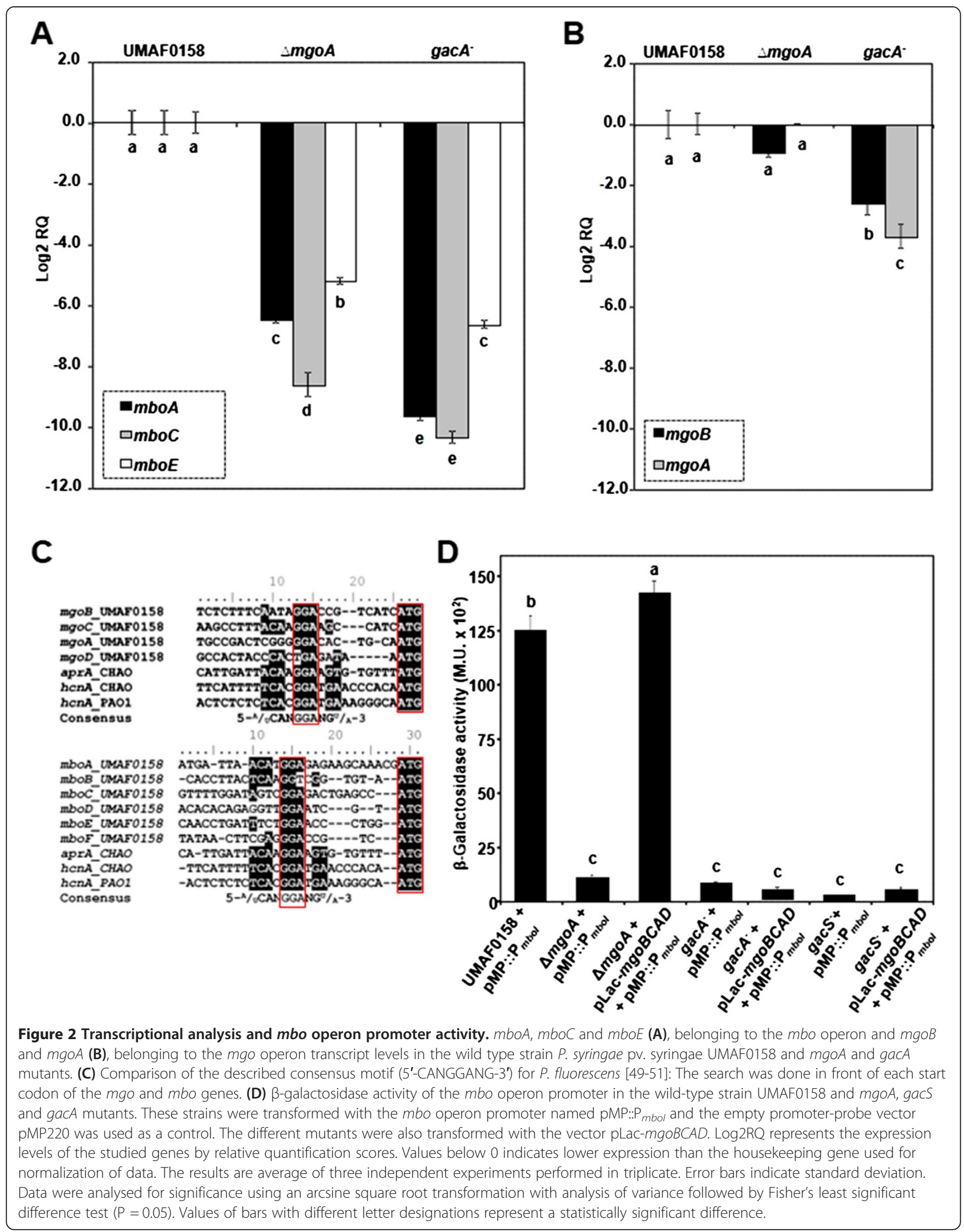


wild type strain, with cell densities of up to $10^{11} \mathrm{cfu} \mathrm{ml}^{-1}$ in liquid medium after $108 \mathrm{~h}$ of growth at $22^{\circ} \mathrm{C}$ (Additional file 2: Figure S1A). In contrast, the gacA mutant presented an altered growth, with cell densities in the stationary phase reaching only $10^{9} \mathrm{cfu} \mathrm{ml}^{-1}$ (Additional file 2: Figure S1A). The dynamics of the mangotoxin production in relation to bacterial growth was followed during four days of incubation. Mangotoxin production was detectable after $24 \mathrm{~h}$ of growth, increased up to 1.4 toxic units (T.U.), then reduced slightly upon entry of the stationary phase and then stabilized (Additional file 2: Figure S1B).

In order to know if the virulence of the derivative mutants $m b o A$ - and $m g o A$ was reduced in comparison with the wild type strain, detached tomato leaflets were artificially inoculated. Artificial inoculation experiments using detached tomato leaflets [4] showed that bacterial growth inside the tomato leaflets of the $m b o A^{-}$and $\triangle m g o A$ mutants as well as their complemented derivatives followed similar dynamics (Additional file 3: Figure S2A). When inoculations were performed, development of necrotic lesions was observed on the leaf. Disease severity, represented by the necrotic area, showed that both mangotoxin defective mutants were less virulent than the wild type UMAF0158 (Additional file 3: Figure S2B and $\mathrm{S} 2 \mathrm{C}$ ). When derivative strains were complemented with the $m b o A$ and $m g o A$ genes disease severity increased but complementation did not fully restore virulence to wild type level (Additional file 3: Figure S2B and S2C).

\section{Mangotoxin production and transcriptional regulation in the gacA and $m g o A$ mutant}

To study the role of $m g o A$ and $g a c A$ in mangotoxin biosynthesis, transcription of the $m b o A C E$ and $m g o B A$ genes was analyzed for the wild type strain, and for the $m g o A$ and gacA derivative mutants. Time course experiments showed that the $m b o$ genes in the wild type are expressed at the highest level after 12 to 24 h (Additional file 4: Figure S3). Therefore all comparisons between wild type and mutants were performed at $18 \mathrm{~h}$ of growth. Transcript levels of the $m b o A C E$ genes after $18 \mathrm{~h}$ of growth were significantly lower in the $g a c A$ and the $m g o A$ mutants than in the wild type (Figure 2A). Also the transcript levels of $m g o B$ and $m g o A$ were significantly lower in the gacA mutant (Figure $2 \mathrm{~B}$ ). The $m g o A$ mutation did not affect transcription of gacS/ gacA (data not shown). Also $m b o A, m b o C$, or $m b o E$ mutations did not significantly affect transcription of $\mathrm{gacS} / \mathrm{gacA}$ or $m g o A$ (data not shown). These results indicate that the GacS/GacA two-component regulatory system affects transcription of both the $m b o$ and $m g o$ genes and that the product of the mgo operon influences transcription of the $m b o$ genes. To further study if the GacS/GacA two-component regulatory system could regulate the $m g o$ and $m b o$ genes via RNA repressor binding proteins [49-51], the upstream

Table 2 Toxic activity of $P$. syringae pv syringae UMAF0158 mutants and $m g \circ$ operon complemented strains

\begin{tabular}{|c|c|c|c|}
\hline \multirow[t]{2}{*}{ Strains } & \multicolumn{2}{|c|}{ E. coli inhibition assay } & \multirow{2}{*}{$\begin{array}{l}\text { Mangotoxir } \\
\text { production }\end{array}$} \\
\hline & PMS & PMS + ornithine & \\
\hline \multicolumn{4}{|c|}{ Wild type strain and derivative mutants } \\
\hline UMAF0158 & + & - & Yes \\
\hline$m b \circ A^{-}$ & $-*$ & $-*$ & No \\
\hline$\triangle m g \circ A$ & - & - & No \\
\hline$g a c A^{-}$ & - & - & No \\
\hline gacs & - & - & No \\
\hline \multicolumn{4}{|c|}{ Transformed with empty vector } \\
\hline UMAF0158 & + & - & Yes \\
\hline$m b o A^{-}$ & $-*$ & $-*$ & No \\
\hline$\triangle m g \circ A$ & - & - & No \\
\hline$g a c A^{-}$ & - & - & No \\
\hline gacs & - & - & No \\
\hline \multicolumn{4}{|c|}{ Transformed with pLac-mgoBCAD } \\
\hline UMAF0158 & ++ & - & Yes \\
\hline$m b \circ A^{-}$ & $-^{*}$ & $-^{*}$ & No \\
\hline$\triangle m g \circ A$ & ++ & - & Yes \\
\hline$g a c A^{-}$ & - & - & No \\
\hline gacs & - & - & No \\
\hline
\end{tabular}

The results are indicated as follows: - absence of inhibition halo, + inhibition halo between 5-10 mm, ++ inhibition halo bigger 10 mm, -* slight toxicity which did not revert in presence of ornithine. Toxic activity, which reverts in the presence of ornithine, denotes the production of mangotoxin. 
regions of the $m g o$ and $m b o$ genes were inspected for the presence of the described consensus motif (5'-CANGGANG-3') previously described in $P$. protegens $\mathrm{CHAO}$ [49]. This motif allows the binding of the repressor to the RNA, and these repressor proteins can be removed by Gac/ Rsm. The complete consensus sequence was not detected upstream of any of the mbo/mgo genes (Figure 2C). However, consensus GGA motifs for binding of the RNA binding proteins [49-51] were detected upstream of the $m b o$ and mgo operons (Figure $2 \mathrm{C}$ ). It must be taken into account that the described consensus sequence is from $P$. protegens [49], and nothing is known yet about the recognition site of RNA binding proteins in P. syringae.

As the transcription of the mgo operon was substantially lower in the gacA mutant (Figure 2B), we subsequently tested whether introduction of extra copies of the mgo operon in the gacS or gacA mutant could restore mangotoxin production. When the mgo operon

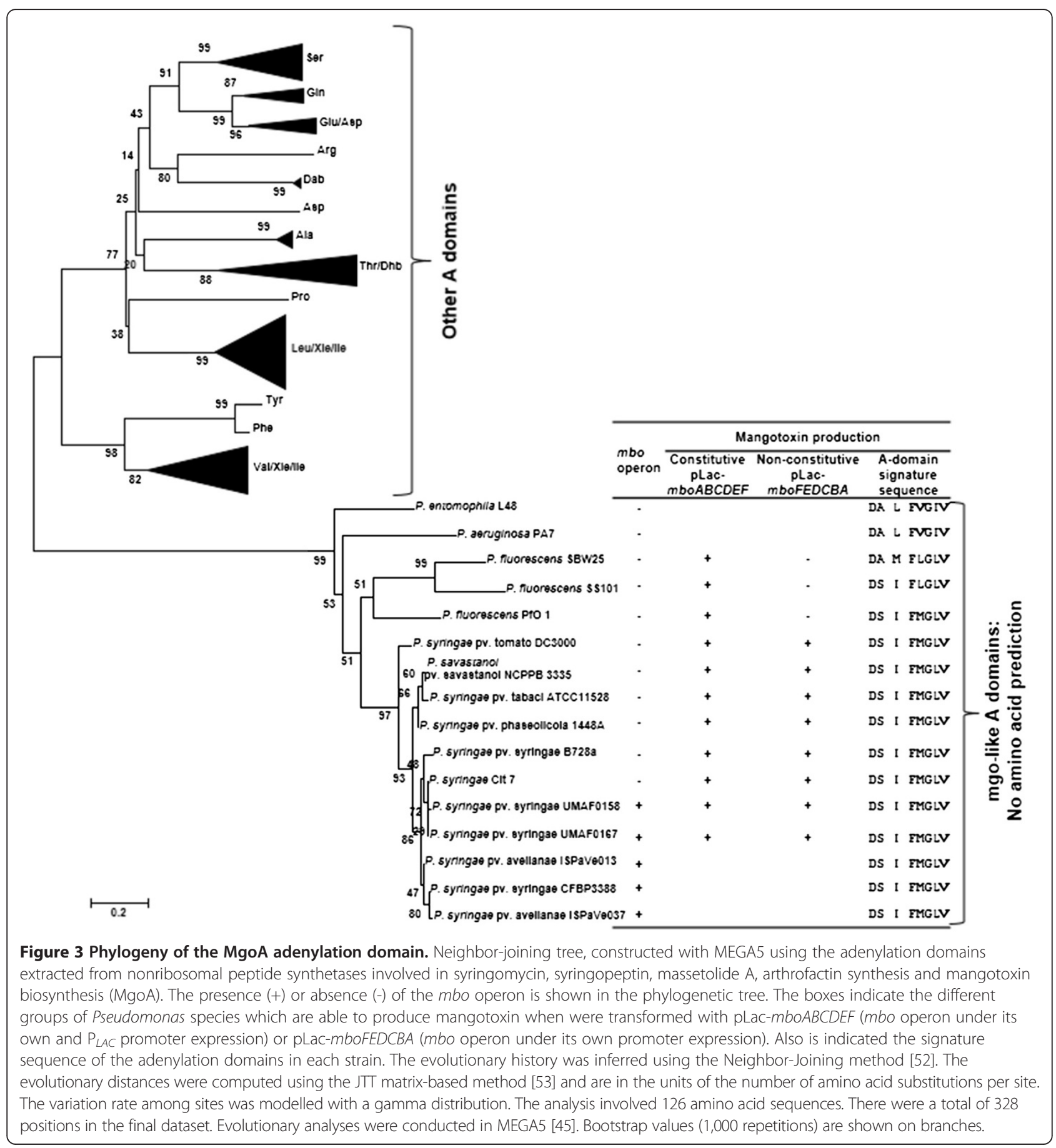


was introduced in the $m g o A$ mutant mangotoxin production was restored, which was not the case for the $m b o A$, gacA and gacS mutants (Table 2).

\section{The $m g o$ operon is a positive regulator of $m b o$ operon transcription}

To further elucidate the role of the mgo operon in the regulation of mangotoxin biosynthesis, expression assays were carried out using a plasmid reporter construction consisting of the $m b o$ operon promoter fused to a promoterless $l a c Z$ gene. When the plasmid reporter was transferred into the wild type strain, high levels of $\beta$-galactosidase activity were found, whereas for the $m g o A, g a c A$ and gacS mutants this activity was substantially lower (Figure 2D). For the $m g o A$ mutant, complementation with the $m g o$ operon restored $\beta$ galactosidase activity to similar levels as in the wild type strain (Figure 2D). In contrast, no restoration of the $\beta$ galactosidase activity was found when the mgo operon was introduced in the $g a c S / g a c A$, confirming results described above (Table 2).

\section{MgoA phylogeny and mangotoxin production in other strains}

The amino acid sequence of a typical non-ribosomal peptide synthetase (NRPS) displays an adenylation (A) domain responsible for recognition and subsequent activation of an amino acid substrate. It also contains the typical thiolation (T) and condensation $(\mathrm{C})$ domains. Finally, the thioesterase (TE) domain releases the final molecule from the NRPS assembly line. Based on the specific signature sequences described previously for A domains, analysis of MgoA did not allow prediction of the amino acid to be activated. Therefore, a phylogenetic analysis was performed with multiple A domains from NRPSs of which activated amino acids are known and with MgoA from other Pseudomonas species (Figure 3 and Additional file 5: Figure S4). The results showed that the A domains from the different MgoA orthologues grouped in the same cluster, separate from other A domains for which the activated amino acid residue is known (Figure 3).

To determine if $m g o A$ present in other Pseudomonas species can regulate the $m b o$ operon, reporter constructs pLac- $m b o A B C D E F$ ( $m b o$ operon under its own and under pLac promoter expression) and pLac-mboFEDCBA ( $m b o$ operon only under its own promoter expression) were used. Firstly, only specific $P$. syringae pathovars harbor the $m b o$ operon, and almost all strains from these pathovars produce mangotoxin [29], with or without the introduction of the mbo operon containing plasmids (Figure 3). Our results showed that other $P$. syringae pathovars, that do not contain the $m b o$ operon, are all able to produce mangotoxin when they were transformed with pLac$m b o A B C D E F$ and pLac-mboFEDCBA (Figure 3). When different $P$. fluorescens strains were transformed with either vector, they only produced mangotoxin when the mbo operon was expressed constitutively but not when they were transformed with the mbo operon with its native promoter (Figure 3).

To further investigate if the mgo operon is able to regulate the expression of the mbo operon, we introduced the $m b o$ operon promoter reporter construct (pMP:: $\mathrm{P}_{m b o I}$ ) and the $m g o$ genes in $P$. protegens Pf-5, which lacks both the $m g o$ and the $m b o$ operons in its genome. Compared to the promoter activity in the wildtype Pf-5 background, a two-fold increase in ectopic $m b o$ promoter activity was observed when Pf-5 was complemented with the mgo operon (Figure 4A). When $P$. protegens Pf-5 was transformed with pLac- $m b o A B C$ $D E F$ ( $m b o$ operon under pLac regulation), it produces mangotoxin. However, when $P$. protegens $\mathrm{Pf}-5$ was transformed with pMP-mboFEDCBA ( $m b o$ operon under only

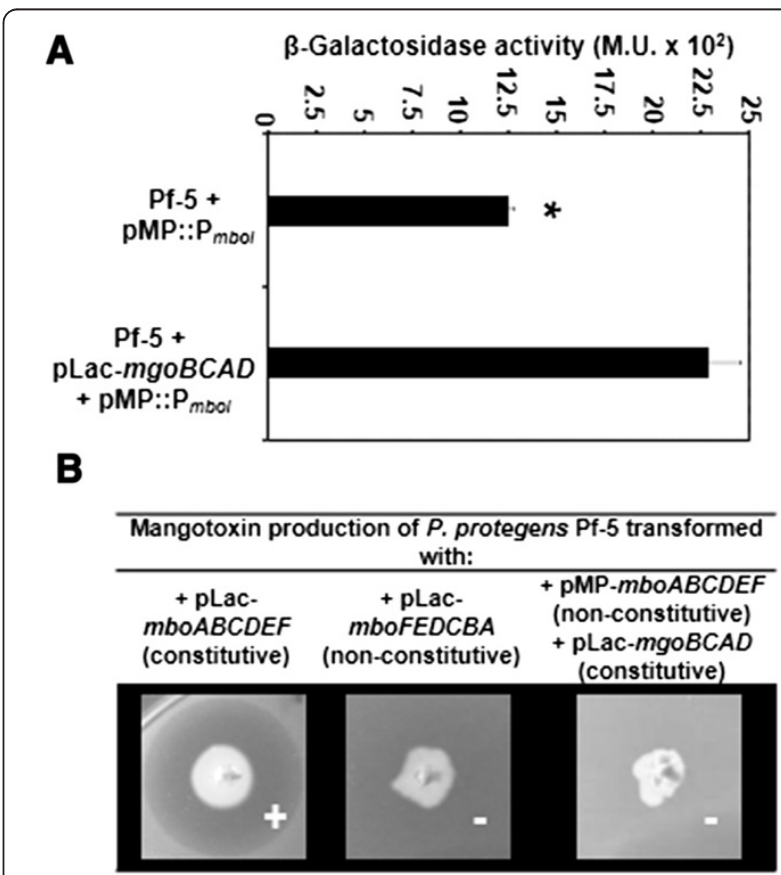

Figure 4 Heterologous expression and production of mangotoxin. (A) The mbo operon promoter activity in P. protegens Pf-5 transformed with the mbo operon promoter (pMP::P $P_{\text {mbol }}$ ) and with the empty promoter-probe vector pMP220 was used as a control. To check the positive regulation of the mgo operon, the strain Pf-5 was transformed with the vector pLac-mgoBCAD. The result is the average of three independent experiments performed in triplicate. Error bars indicate standard deviation. (B) Mangotoxin production of $P$. protegens Pf- 5 transformed with pLac-mboABCDEF (mbo operon under its own and $P_{L A C}$ promoter expression), pLacmboFEDCBA ( $m b o$ operon under its own promoter expression) and pLac-mgoBCAD (mgo operon under its own and $\mathrm{P}_{L A C}$ promoter expression) and PMP220-mboABCDEF (mbo operon under its own promoter expression). Data were analysed for significance using a Student's $t$-test $(P=0.05)$. Value of bar with an asterisk designation represent a statistically significant difference to the other bar value. 
its own promoter expression) it was not able to produce detectable amounts of mangotoxin, neither in absence nor in presence of the $m g o$ operon of $P$. syringae pv. syringae UMAF0158 (Figure 4B). Therefore, the presence of the $m b o$ and $m g o$ operons in P. protegens Pf-5 would be not sufficient for the production of detectable amounts of mangotoxin.

\section{Discussion}

The results of our study show that the regulation of mangotoxin biosynthesis in the plant pathogenic $P$. syringae pv. syringae strain UMAF0158 is governed by a complex interplay between the GacS/GacA twocomponent regulatory system, the nonribosomal peptide synthetase $m g o A$ and the mangotoxin biosynthesis operon mbo. We showed that disruption of the mbo biosynthesis genes leads to reduced virulence. Introduction of the mbo operon in these biosynthesis mutants restored mangotoxin production but did not lead to full restoration of virulence on tomato leaflets. Multiple copies of the plasmid with the mbo operon could lead to overproduction of mangotoxin which may affect the regulation or production of other virulence factors such as syringomycin and syringopeptin.

Taken together the obtained results of this work and the previously described data $[4,6,7]$, a simplified model for the interplay among these genes can be constructed (Figure 5). In this model, the GacS/GacA two-component regulatory system receives a yet unknown signal that activates a set of small RNAs $[8,50,54]$. The expression of genes regulated by the GacS/GacA might be mediated through the Rsm pathway $[55,56]$. In fact, components of this pathway such as the three small RNAs RsmX, RsmY and RsmZ and two RNA-binding proteins (RsmA and RsmE) were found in the genome of $P$. syringae pv. syringae UMAF0158 (Unpublished data). Transcriptional analysis of the $m g o, m b o$ and $g a c$ genes showed that the $m b o$ genes were markedly down-regulated in both the gacA and $m g o A$ mutants. On the other hand, the transcriptional levels of $m g o B$ and $m g o A$, also showed down-regulation in the gacA mutant, indicating that the mgo operon is also under regulation by the GacS/GacA two-component regulatory system. These data suggest that GacS/GacA is regulating the $m b o$ operon expression via the $m g o$ operon, however direct regulation of the $m b o$ operon by the two-component regulatory system gacS/gacA cannot be excluded (Figure 5).

Transcriptional analysis with a lacZ fusion on the promoter of the $m b o$ operon $\left(\mathrm{P}_{m b o l}\right)$, revealed that the product of the $m g o$ operon could acts as positive regulator of $m b o$ transcription. Interestingly, the $p v f C$ gene (homologue of $m g o A$ ) is considered a regulator of virulence in $P$. enthomophila, but appears not to be part of the GacS/GacA regulatory cascade [28]. In strain UMAF0158, introduction of the mgo operon in a gac mutant could not restore mangotoxin production or mbo-promoter activity, suggesting that next

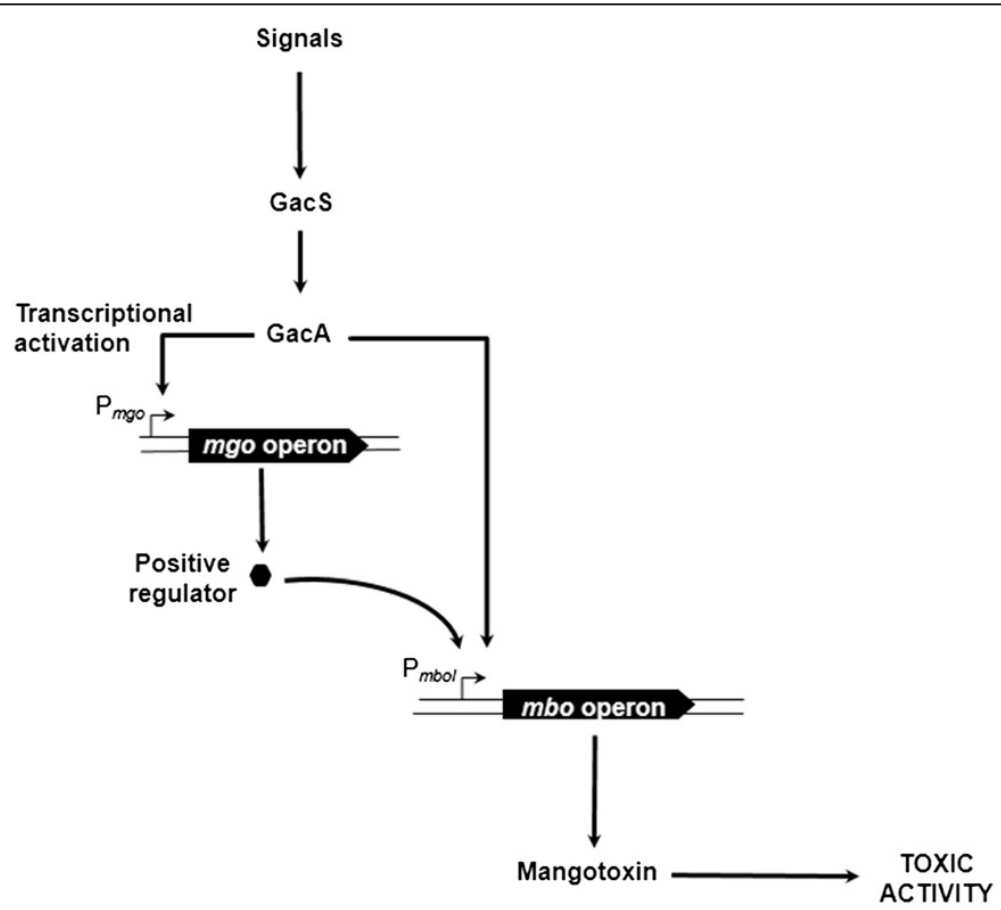

Figure 5 Proposed model for regulation of mangotoxin biosynthesis in P. syringae pv. syringae. In this model, GacS/GacA two-component regulatory system activates directly or indirectly the transcription of the mgo operon. And the mgo operon could synthetize a positive regulator of the mbo operon transcription. The mbo operon produces mangotoxin which acts as virulence factor. 
to the mgo operon, additional factors are regulated by the gac system that influence mangotoxin production. It is worth noting that $P$. entomophila and $P$. syringae pv. syringae harbor two different genetic backgrounds, adapted to different environments. The first is found in diverse environments such as soil, aquatic ecosystems, rhizosphere, and in pathogenic interactions with Drosophila melanogaster [57]. The second is adapted for plant infection and epiphytic survival [3]. Therefore, the regulatory roles of these orthologues can substantially differ between these two Pseudomonas species. On the other hand, the fact that both PvfC and MgoA are involved in the regulation of virulence could indicate that in other Pseudomonas spp. these factors would be involved in the regulation of virulence and/or secondary metabolite production.

Phylogenetic analysis of MgoA and the adenylation domains suggested an evolutionary specialization of this protein into the Pseudomonas genus. In this context, it is worth noting that the transformation of the mbo operon under the expression of its own promoter only confers mangotoxin production in the P. syringae group and not in the P. fluorescens group. Therefore, it seems that the NRPS MgoA is involved in different signal transduction pathways depending of the Pseudomonas species. In the case of $P$. syringae, MgoA appears to activate mangotoxin production. It remains to be studied if MgoA is also involved in the regulation and production of other antimetabolites in the P. syringae group, such as tabtoxin and phaseolotoxin. The positive regulation of the $m b o$ operon promoter activity in the presence of the mgo operon in Pf-5, combined with the lack of detectable amounts of mangotoxin suggests that additional factors for mangotoxin biosynthesis or its export are not present in the P. fluorescens group.

\section{Conclusions}

In summary, for $P$. syringae pv. syringae UMAF0158, the GacS/GacA two-component system regulates transcription of the $m g o$ and $m b o$ operons and thereby mangotoxin biosynthesis. At the same time, the mgo operon product seems to act as a positive regulator of the $m b o$ operon. The proposed model for mangotoxin biosynthesis is a simplified and initial overview of the interaction between the gac, mgo and $m b o$ gene products based on the results obtained in the current study. This is the first evidence of the interplay between MgoA and the GacS/GacA two-component regulatory system in the regulation of the mangotoxin biosynthesis.

\section{Ethics statement}

We the authors hereby declare that the research performed with plants has been conducted in accordance with institutional, national and international guidelines.

\section{Additional files}

\begin{abstract}
Additional file 1: Table S1. Primers used in this study.
Additional file 2: Figure S1. Growth characteristics of $P$. syringae pv. syringae strain UMAF0158 and the derivatives $\mathrm{mgoA}$ and gacA mutants. (A) Growth of the wild type strain UMAF0158 and the mgoA ( $\triangle \mathrm{mgOA})$ and gacA (2ßB7) mutants at $22^{\circ} \mathrm{C}$ in PMS. At each time point, the bacterial density was estimated by serial dilutions and colony counts on plates of selective medium and expressed as log cfu ml-1 of culture. (B) UMAF0158 mangotoxin production at $22^{\circ} \mathrm{C}$ in PMS. At each time point, the mangotoxin production was estimated using cell-free filtrate and represented as the previously defined toxic units (T.U.). The dashed line represents the detection limit of the technique. Mean values for three replicates are given; the error bars represent the standard errors of the mean.
\end{abstract}

Additional file 3: Figure S2. Virulence analysis of the wild type strain P. syringae pv. syringae UMAF0158 and corresponding derivatives using a detached tomato leaf assay. (A) In planta growth inside the tomato leaflets after $\mathrm{H}_{2} \mathrm{O}_{2}$ surface disinfection of the wild type strain UMAF0158, $m g o A$ and $m b o A$ mutants, and their respective complemented derivatives. (B) Severity of necrotic symptoms (necrotic area) on tomato leaflets inoculated with wild type strain UMAF0158, the mutants in mboA and $m g \circ A$ with their respective complemented derivatives. The total necrotic area $\left(\mathrm{mm}^{2}\right)$ from 30 inoculated points on tomato leaflets was measured 10 days after inoculation and used to compare the severity of necrotic symptoms produced by the different strains. (C) Representative pictures of the necrotic lesions produced by the wild type strain and the different mutants at $10 \mathrm{dpi}$. Different letters denote statistically significant differences at $p=0.05$, according to analysis of variance followed by Fisher's least significant difference test.

Additional file 4: Figure S3. mboACE transcript levels in the wild type strain UMAF0158. Relative expression of the genes involved in the mangotoxin biosynthesis at the different time points during the growth curve. For each time point, mean values of four biological replicates are given; the error bars represent the standard errors of the mean.

Additional file 5: Figure S4. Phylogenetic analysis of the MgoA of different Pseudomonas spp. Neighbor-joining tree was constructed with MEGA5 using a partial sequence of MgoA. The boxes indicate the different groups of Pseudomonas and the presence $(m b o+)$ or absence ( $m b o$-) of the mbo operon. The evolutionary history was inferred using the Neighbor-Joining method [52]. The evolutionary distances were computed using the JT matrix-based method [53] and are in the units of the number of amino acid substitutions per site. The rate variation among sites was modelled with a gamma distribution. The analysis involved 126 amino acid sequences. There were a total of 1015 positions in the final dataset. Evolutionary analyses were conducted in MEGA5 [45]. Burkholderia cenocepacia J2315 was used as the outgroup. Bootstrap values (1,000 repetitions) are shown on the branches.

\section{Competing interests}

We the authors hereby declare that there is no conflict of interests concerning this manuscript.

\section{Authors' contributions}

VJC, MV, EA, AV, JMR and FMC conceived the study. VJC and EA did all the cloning and genetics of this study. VJC and MV did the Q-PCR experiments and analysis. VJC and JAG did complementation and reporter construct experiments. JMR and AV supported the research. VJC, MV, JMR and FMC wrote the manuscript. VJC, EA, MV, AV, JMR and FMC coordinated and critically revised the manuscript. All authors read and approved the manuscript.

\section{Acknowledgements}

This work was supported by grants from the Regional Government of Andalucía (Spain), grants from CICE - Junta de Andalucía, Ayudas Grupo PAIDI AGR-169, and Proyecto de Excelencia (P07-AGR-02471) and Plan Nacional de I + D + I del Ministerio de Ciencia e Innovacion (AGL2011-30354-C02-01) cofinanced by FEDER (EU). Plan Propio of the University of Málaga funded a stay of VJC in the Wageningen University, The Netherlands. This is publication No. 5584 of the Netherlands Institute of Ecology (NIOO-KNAW). VJC was 
supported with a fellowship from Junta de Andalucía, Spain, and EA with a JAEDoc grant from the CSIC, which was co-financed by ESF. We also thank Cayo Ramos and his group for their help in this research.

\section{Author details}

'Departamento de Microbiología, Facultad de Ciencias, Instituto de Hortofruticultura Subtropical y Mediterránea "La Mayora"-Universidad de Málaga-Consejo Superior de Investigaciones Científicas (IHSM-UMA-CSIC), Universidad de Málaga, Campus de Teatinos, 29071 Málaga, Spain. ${ }^{2}$ Instituto de Hortofruticultura Subtropical y Mediterránea "La Mayora"-Universidad de Málaga-Consejo Superior de Investigaciones Científicas (IHSM-UMA-CSIC), Estación Experimental La Mayora, Algarrobo-Costa, 29750 Málaga, Spain. ${ }^{3}$ Laboratory of Phytopathology, Wageningen University, 6708 PB Wageningen, The Netherlands. ${ }^{4}$ Department of Microbial Ecology, The Netherlands Institute of Ecology (NIOO-KNAW), Wageningen, The Netherlands. ${ }^{5}$ BIOMERIT Research Centre, School of Microbiology, University College Cork, National University of Ireland, Cork, Ireland.

Received: 10 December 2013 Accepted: 12 February 2014 Published: 21 February 2014

\section{References}

1. Kennelly MM, Cazorla FM, de Vicente A, Ramos C, Sundin GW: Pseudomonas syringae diseases of fruit trees: progress toward understanding and control. Plant Dis 2007, 91(1):4-17.

2. Arrebola E, Cazorla FM, Durán VE, Rivera E, Olea F, Codina JC, Pérez-García A, de Vicente A: Mangotoxin: a novel antimetabolite toxin produced by Pseudomonas syringae inhibiting ornithine/arginine biosynthesis. Physiol Mol Plant Path 2003, 63(3):117-127.

3. Cazorla FM, Torés JA, Olalla L, Pérez-García A, Farré JM, de Vicente A: Bacterial apical necrosis of mango in southern Spain: a disease caused by Pseudomonas syringae pv. syringae. Phytopathology 1998, 88(7):614-620.

4. Arrebola E, Cazorla FM, Romero D, Pérez-García A, de Vicente A: A nonribosomal peptide synthetase gene $(m g \circ A)$ of Pseudomonas syringae pv. syringae is involved in mangotoxin biosynthesis and is required for full virulence. Mol Plant-Microbe Interact 2007, 20(5):500-509.

5. Arrebola E, Cazorla FM, Codina JC, Gutiérrez-Barranquero JA, Pérez-García A, de Vicente A: Contribution of mangotoxin to the virulence and epiphytic fitness of Pseudomonas syringae pv. syringae. Int Microbiol 2009, 12(1139-6709):87-95.

6. Carrión VJ, Arrebola E, Cazorla FM, Murillo J, de Vicente A: The mbo operon is specific and essential for biosynthesis of mangotoxin in Pseudomonas syringae. PLoS One 2012, 7(5):e36709.

7. Arrebola E, Carrión VJ, Cazorla FM, Pérez-García A, Murillo J, de Vicente A Characterisation of the mgo operon in Pseudomonas syringae pv. syringae UMAF0158 that is required for mangotoxin production. BMC Microbiol 2012, 12(1):10.

8. Heeb S, Haas D: Regulatory roles of the GacS/GacA two-component system in plant-associated and other gram-negative bacteria. Mol Plant-Microbe Interact 2001, 14(12):1351-1363.

9. Chancey ST, Wood DW, Pierson LS: Two-component transcriptional regulation of $\mathrm{N}$-acyl-homoserine lactone production in Pseudomonas aureofaciens. Appl Environ Microbiol 1999, 65(6):2294-2299.

10. Kay E, Humair B, Dénervaud V, Riedel K, Spahr S, Eberl L, Valverde C, Haas D: Two GacA-dependent small RNAs modulate the quorum-sensing response in Pseudomonas aeruginosa. J Bacteriol 2006, 188(16):6026-6033.

11. Corbell N, Loper JE: A global regulator of secondary metabolite production in Pseudomonas fluorescens Pf-5. J Bacteriol 1995, 177(21):6230-6236.

12. Whistler CA, Pierson LS III: Repression of phenazine antibiotic production in Pseudomonas aureofaciens strain 30-84 by RpeA. J Bacteriol 2003, 185 (13):3718-3725.

13. Hassan KA, Johnson A, Shaffer BT, Ren Q, Kidarsa TA, Elbourne LDH, Hartney S, Duboy R, Goebel NC, Zabriskie TM, Paulsen IT, Loper JE: Inactivation of the GacA response regulator in Pseudomonas fluorescens Pf-5 has far-reaching transcriptomic consequences. Environ Microbiol 2010, 12(4):899-915.

14. Cheng X, de Bruijn I, van der Voort M, Loper JE, Raaijmakers JM: The Gac regulon of Pseudomonas fluorescens SBW25. Environ Microbiol Rep 2013, 5(4):608-619.

15. Parkins MD, Ceri H, Storey DG: Pseudomonas aeruginosa GacA, a factor in multihost virulence, is also essential for biofilm formation. Mol Microbiol 2001, 40(5):1215-1226.
16. Petrova OE, Sauer $\mathrm{K}$ : The novel two-component regulatory system BfiSR regulates biofilm development by controlling the small RNA rsmZ through CafA. J Bacteriol 2010, 192(20):5275-5288.

17. Muller J, Shukla S, Jost K, Spormann A: The $m x d$ operon in Shewanella oneidensis MR-1 is induced in response to starvation and regulated by ArcS/ArcA and BarA/UvrY. BMC Microbio/ 2013, 13(1):119.

18. Lu S-E, Scholz-Schroeder BK, Gross DC: Characterization of the salA, syrF, and syrG regulatory genes located at the right border of the syringomycin gene cluster of Pseudomonas syringae pv. syringae. Mol Plant-Microbe Interact 2002, 15(1):43-53.

19. Wang N, Lu S-E, Wang J, Chen ZJ, Gross DC: The expression of genes encoding lipodepsipeptide phytotoxins by Pseudomonas syringae pv. syringae is coordinated in response to plant signal molecules. Mol Plant-Microbe Interact 2006, 19(3):257-269.

20. Lu S-E, Wang N, Wang J, Chen ZJ, Gross DC: Oligonucleotide microarray analysis of the SalA regulon controlling phytotoxin production by Pseudomonas syringae pv. syringae. Mol Plant-Microbe Interact 2005, 18(4):324-333.

21. Barta TM, Kinscherf TG, Willis DK: Regulation of tabtoxin production by the lemA gene in Pseudomonas syringae. J Bacterio/ 1992, 174(9):3021-3029.

22. Bender CL, Alarcón-Chaidez F, Gross DC: Pseudomonas syringae phytotoxins: mode of action, regulation, and biosynthesis by peptide and polyketide synthetases. Microbiol Mol Biol Rev 1999, 63(2):266-292.

23. de la Torre-Zavala S, Aguilera S, Ibarra-Laclette E, Hernandez-Flores JL, Hernández-Morales A, Murillo J, Alvarez-Morales A: Gene expression of Pht cluster genes and a putative non-ribosomal peptide synthetase required for phaseolotoxin production is regulated by GacS/GacA in Pseudomonas syringae pv. phaseolicola. Res Microbiol 2011, 162(5):488-498.

24. Willis DK, Hrabak EM, Rich JJ, Barta TM, Lindow SE, Panopoulos NJ: Isolation and characterization of a Pseudomonas syringae pv. syringae mutant deficient in lesion formation on bean. Mol Plant-Microbe Interact 1990, 3(3):149-156.

25. Chatterjee A, Cui Y, Yang H, Collmer A, Alfano JR, Chatterjee AK: GacA, the response regulator of a two-component system, acts as a master regulator in Pseudomonas syringae pv. tomato DC3000 by controlling regulatory RNA, transcriptional activators, and alternate sigma factors. Mol Plant-Microbe Interact 2003, 16(12):1106-1117.

26. Lindeberg $M$, Myers CR, Collmer A, Schneider DJ: Roadmap to new virulence determinants in Pseudomonas syringae: insights from comparative genomics and genome organization. Mol Plant-Microbe Interact 2008, 21(6):685-700.

27. Loper JE, Hassan KA, Mavrodi DV, Davis EW II, Lim CK, Shaffer BT, Elbourne LDH, Stockwell VO, Hartney SL, Breakwell K, Henkels MD, Tetu SG, Rangel LI, Kidarsa TA, Wilson NL, van de Mortel JE, Song C, Blumhagen R, Radune D, Hostetler JB, Brinkac LM, Durkin AS, Kluepfel DA, Wechter WP, Anderson AJ Kim YC, Pierson LS III, Pierson EA, Lindow SE, Kobayashi DY, et al: Comparative genomics of Plant-Associated Pseudomonas spp.: insights into diversity and inheritance of traits involved in multitrophic interactions. PLOS Genet 2012, 8(7):e1002784.

28. Vallet-Gely I, Opota O, Boniface A, Novikov A, Lemaitre B: A secondary metabolite acting as a signalling molecule controls Pseudomonas entomophila virulence. Cell Microbiol 2010, 12(11):1666-1679.

29. Carrión VJ, Gutiérrez-Barranquero JA, Arrebola E, Bardaji L, Codina JC, de Vicente A, Cazorla FM, Murillo J: The mangotoxin biosynthetic operon ( $\mathrm{mbo}$ ) is specifically distributed within Pseudomonas syringae Genomospecies 1 and was acquired only once during evolution. Appl Environ Microbiol 2013, 79(3):756-767.

30. Gutiérrez-Barranquero JA, Carrión VJ, Murillo J, Arrebola E, Arnold DL, Cazorla FM, de Vicente A: A Pseudomonas syringae diversity survey reveals a differentiated phylotype of the pathovar syringae associated with the mango host and mangotoxin production. Phytopathology 2013, 103(11):1115-1129.

31. King EO, Ward MK, Raney DE: Two simple media for the demonstration of pyocyanin and fluorescin. J Lab Clin Med 1954, 44(2):301-307.

32. Gasson MJ: Indicator technique for antimetabolic toxin production by phytopathogenic species of Pseudomonas. Appl Environ Microbiol 1980 39(1):25-29.

33. Hanahan D: Studies on transformation of Escherichia coli with plasmids. J M Biol 1983, 166(4):557-580.

34. Feil H, Feil WS, Chain P, Larimer F, DiBartolo G, Copeland A, Lykidis A, Trong S, Nolan M, Goltsman E, Thiel J, Malfatti S, Loper JE, Lapidus A, Detter JC, Land M, Richardson PM, Kyrpides NC, Ivanova N, Lindow SE: Comparison of the complete genome sequences of Pseudomonas syringae pv. syringae B728a and pv. tomato DC3000. Proc Natl Acad Sci USA 2005, 102(31):11064-11069. 
35. Howell CR, Stipanovic RD: Suppression of Pythium ultimum-induced damping-off of cotton seedlings by Pseudomonas fluorescens and its antibiotic, pyoluteorin. Phytopathology 1980, 70:712-715.

36. Kovach ME, Elzer PH, Steven Hill D, Robertson GT, Farris MA, Roop li RM, Peterson KM: Four new derivatives of the broad-host-range cloning vector pBBR1MCS, carrying different antibiotic-resistance cassettes. Gene 1995, 166(1):175-176.

37. Spaink HP, Okker RJH, Wijffelman CA, Pees E, Lugtenberg BJJ: Promoters in the nodulation region of the Rhizobium leguminosarum Sym plasmid pRL1JI. Plant Mol Biol 1987, 9(1):27-39.

38. Sambrook J, Russel DW: Molecular Cloning: A Laboratory Manual. Cold Spring Harbor, NY: Cold Spring Harbor Laboratory Press; 2001.

39. de Bruijn I, de Kock MJD, de Waard P, van Beek TA, Raaijmakers JM: Massetolide A biosynthesis in Pseudomonas fluorescens. J Bacteriol 2008, 190(8):2777-2789.

40. de Bruijn I, Raaijmakers JM: Regulation of cyclic lipopeptide biosynthesis in Pseudomonas fluorescens by the ClpP protease. J Bacteriol 2009, 191(6):1910-1923.

41. Miller JH: Experiments in Molecular Genetics. Cold Spring Harbor, NY: Cold Spring Harbor Laboratory; 1972

42. Altschul SF, Gish W, Miller W, Myers EW, Lipman DJ: Basic local alignment search tool. J Mol Biol 1990, 215(3):403-410.

43. Bachmann $\mathrm{BO}$, Ravel J: Chapter 8 methods for in silico prediction of microbial polyketide and nonribosomal peptide biosynthetic pathways from DNA sequence data. In Method Enzymol. Edited by David AH. PA: Academic Press; 2009:181-217. vol. Volume 458.

44. de Bruijn I, de Kock MJD, Yang M, de Waard P, van Beek TA, Raaijmakers JM: Genome-based discovery, structure prediction and functional analysis of cyclic lipopeptide antibiotics in Pseudomonas species. Mol Microbiol 2007, 63(2):417-428

45. Tamura K, Peterson D, Peterson N, Stecher G, Nei M, Kumar S: MEGA5: Molecular evolutionary genetics analysis using maximum likelihood, evolutionary distance, and maximum parsimony methods. Mol Biol Evol 2011, 28(10):2731-2739.

46. Rutherford K, Parkhill J, Crook J, Horsnell T, Rice P, Rajandream MA, Barrell B: Artemis: sequence visualization and annotation. Bioinformatics 2000 16(10):944-945.

47. Carver TJ, Rutherford KM, Berriman M, Rajandream MA, Barrell BG, Parkhill J: ACT: the Artemis comparison tool. Bioinformatics 2005, 21(16):3422-3423.

48. Abbott JC, Aanensen DM, Rutherford K, Butcher S, Spratt BG: WebACT-an online companion for the Artemis Comparison Tool. Bioinformatics 2005, 21(18):3665-3666.

49. Blumer C, Heeb S, Pessi G, Haas D: Global GacA-steered control of cyanide and exoprotease production in Pseudomonas fluorescens involves specific ribosome binding sites. Proc Natl Acad Sci USA 1999, 96(24):14073-14078

50. Valverde $C$, Lindell $M$, Wagner EGH, Haas D: A repeated GGA motif is critical for the activity and stability of the riboregulator RsmY of Pseudomonas fluorescens. J Biol Chem 2004, 279(24):25066-25074.

51. Dubey AK, Baker CS, Suzuki K, Jones AD, Pandit P, Romeo T, Babitzke P: CsrA regulates translation of the Escherichia coli carbon starvation gene, $\operatorname{cst} A$, by blocking ribosome access to the $\operatorname{cst} A$ transcript. J Bacteriol 2003, 185(15):4450-4460.

52. Saitou N, Nei M: The neighbor-joining method: a new method for reconstructing phylogenetic trees. Mol Biol Evol 1987, 4(4):406-425.

53. Jones DT, Taylor WR, Thornton JM: The rapid generation of mutation data matrices from protein sequences. Comput Appl Biosci 1992, 8(3):275-282.

54. Lapouge K, Sineva E, Lindell M, Starke K, Baker CS, Babitzke P, Haas D: Mechanism of $h c n A$ mRNA recognition in the Gac/Rsm signal transduction pathway of Pseudomonas fluorescens. Mol Microbiol 2007, 66(2):341-356.

55. Lapouge K, Schubert M, Allain FHT, Haas D: Gac/Rsm signal transduction pathway of gamma-proteobacteria: from RNA recognition to regulation of social behaviour. Mol Microbio/ 2008, 67(2):241-253.
56. Kay E, Dubuis C, Haas D: Three small RNAs jointly ensure secondary metabolism and biocontrol in Pseudomonas fluorescens CHA0. Proc Natl Acad Sci USA 2005, 102(47):17136-17141.

57. Vodovar N, Vallenet D, Cruveiller S, Rouy Z, Barbe V, Acosta C, Cattolico L, Jubin C, Lajus A, Segurens B, Vacherie B, Wincker P, Weissenbach J, Lemaitre B, Médigue $C$, Boccard F: Complete genome sequence of the entomopathogenic and metabolically versatile soil bacterium Pseudomonas entomophila. Nat Biotechnol 2006, 24(6):673-679.

doi:10.1186/1471-2180-14-46

Cite this article as: Carrión et al:: Mangotoxin production of Pseudomonas syringae pv. syringae is regulated by MgoA. BMC Microbiology 2014 14:46.

\section{Submit your next manuscript to BioMed Central and take full advantage of:}

- Convenient online submission

- Thorough peer review

- No space constraints or color figure charges

- Immediate publication on acceptance

- Inclusion in PubMed, CAS, Scopus and Google Scholar

- Research which is freely available for redistribution
C Biomed Central 